\title{
Auditing and standardising care for young people with diabetes: beginning a process to improve outcomes
}

\author{
Mark A Sperling
}

Clear goals, uniform practices, and expectations influence outcomes for young people with diabetes
$\mathrm{D}$ iabetes mellitus is a state of dysregulated metabolism caused by varying degrees of insulin deficiency, compounded by resistance to its metabolic actions. In type 1 diabetes, the most common form in children and adolescents, severe insulin deficiency caused by an autoimmune process triggered by environmental factors ultimately leads to near total loss of insulin secretion, necessitating its replacement. Type 2 diabetes, associated with insulin resistance, obesity and genetic or acquired defects in insulin secretion, affects only $5-10 \%$ of children and adolescents with diabetes. ${ }^{1}$ Hyperglycaemia is the most convenient feature to check in patients, by measuring blood glucose levels several times each day; $\mathrm{HbA}_{1 \mathrm{c}}$ levels can be assessed for longer term monitoring, while abnormalities in protein and fat metabolism are checked periodically. The overall costs to any national health service of daily treatment and later complications are staggering: and, as the numbers of people with types 1 and 2 diabetes are increasing worldwide, so too are the costs. $^{2}$

The micro- and macrovascular complications of diabetes are related to the degree of metabolic control; moreover, stricter metabolic control at the onset of type 1 diabetes imparts long lasting metabolic benefits that delay complications, even if control later deteriorates ("metabolic memory"). ${ }^{3}$ Avoiding large swings in blood glucose levels in people with near normal average levels also delays the development of complications. ${ }^{4}$ Strict metabolic control is therefore fostered by the standards of care recommended by national and international societies, including those in Australia.,

The consensus is that $\mathrm{HbA}_{1 \mathrm{c}}$ levels in children and adolescents with diabetes should be below $58 \mathrm{mmol} / \mathrm{mol}$ and that variations in glucose levels be minimised..$^{4-6}$ Achieving this goal remains challenging. Success requires three elements: providing insulin in a manner that mimics normal physiology as closely as possible; integrating treatment with age-appropriate nutrition and exercise regimens; and the family and medical team mutually agreeing upon appropriate goals.

The current standard of insulin delivery is multiple daily injections, consisting of one or two basal injections and three or more injections of short-acting insulin to cover meals and snacks. The twice-daily combination of short- and longer acting insulin constitutes the minimal level of care, and is often reserved for patients with special needs. ${ }^{7}$ Continuous subcutaneous insulin infusion (CSII) by pumps that adjust for changes in blood glucose levels, and continuous glucose level monitoring by implanted subcutaneous sensors can further improve metabolic control; newer technologies permit parental regulation of insulin delivery

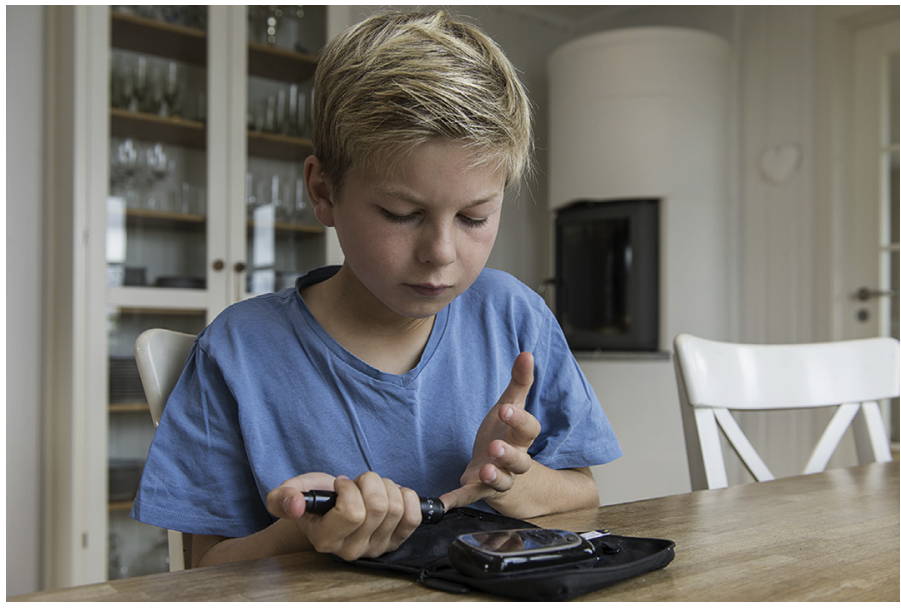

via pumps by remote control. ${ }^{7} \mathrm{CSII}$ is recommended from the onset of diabetes by some centres, while others suggest instituting it after an initial "honeymoon period". Each approach requires educating the patient and their family and the assistance of specialist teams; socio-economic factors such as income, family coherence, education, and mutual trust between the family unit and their caregivers also affect outcomes. Even under ideal circumstances, life with type 1 diabetes requires a discipline that few have.

In this issue of the $M J A$, the Australasian Diabetes Data Network report the first national audit of data on children and adolescents with type 1 diabetes, based on data for the 2015 calendar year from five major Australian paediatric diabetes centres staffed by internationally recognised specialists, encompassing data for more than 3000 people under 18 years of age with type 1 diabetes of at least 12 months' duration. ${ }^{8}$ The results provide a snapshot of paediatric diabetes in Australia, demonstrate the feasibility of using nationally collated data for benchmarking, and to identify both areas of success and those that need improvement. Overall, $\mathrm{HbA}_{1 \mathrm{c}}$ level targets were achieved by only $27 \%$ of patients. Mean $\mathrm{HbA}_{1 \mathrm{c}}$ levels were lower in children under 6 than in adolescents (14-18 years of age), probably reflecting greater parental control in the younger children. This low overall level of control is of some concern, especially in adolescents, but it reflects how difficult it is to attain targets, and is also consistent with results from other centres. ${ }^{9}$ Almost one in five children were receiving twice-daily insulin injections; the disparity between the various centres in the prevalence of this approach probably reflects local preferences more than the accommodation of patients' needs. There were also variations in the adoption of CSII, which appeared to achieve better glycaemic control. One-third of the children were overweight or obese, indicating the need for a national review of nutrition and exercise guidelines.

The studies cited by Phelan and her co-authors, ${ }^{8}$ as well as more recent reports, indicate that clear goals, uniform practices, and 
expectations influence outcomes for young people with diabetes. ${ }^{10}$ Their results point to the need, feasibility and opportunity for harmonising data collection, for identifying deficiencies in treatment, for seeking more resources when appropriate, and for implementing more uniform treatment strategies across centres.

Competing interests: No relevant disclosures

Provenance: Commissioned; externally peer reviewed.

(c) 2017 AMPCo Pty Ltd. Produced with Elsevier B.V. All rights reserved.

1 Craig ME, Jefferies C, Dabelea D, et al. ISPAD Clinical Practice Consensus Guidelines 2014. Definition, epidemiology and classification of diabetes in children and adolescents. Pediatr Diabetes 2014; 15 Suppl 20: 4-17.

2 da Rocha Fernandes J, Ogurtsova K, Linnenkamp U, et al. IDF Diabetes Atlas estimates of 2014 global health expenditures on diabetes. Diabetes Res Clin Pract 2016; 117: 48-54.

3 Chen Z, Miao F, Paterson AD, et al. Epigenomic profiling reveals an association between persistence of DNA methylation and metabolic memory in the DCCT/EDIC type 1 diabetes cohort. Proc Natl Acad Sci USA 2016; 113: E3002-E3011.
4 Virk SA, Donaghue $\mathrm{KC}$, Cho YH, et al. Association between $\mathrm{HbA}_{\mathrm{lc}}$ variability and risk of microvascular complications in adolescents with type 1 diabetes. I Clin Endocrinol Metab 2016; 101: 3257-3263.

5 Craig ME, Twigg SM, Donaghue KC, et al; for the Australian Type 1 Diabetes Guidelines Expert Advisory Group. National evidence-based clinical care guidelines for type 1 diabetes in children, adolescents and adults. Canberra: Australian Government Department of Health and Ageing, 2011. https://diabetessociety.com.au/downloads/ Typelguidelines (7Feb11).pdf (accessed Nov 2016).

6 Bjornstad P, Pyle L, Nguyen N, et al. Achieving International Society for Pediatric and Adolescent Diabetes and American Diabetes Association clinical guidelines offers cardiorenal protection for youth with type 1 diabetes. Pediatr Diabetes 2015; 16: 22-30

7 Danne T, Bangstad H-J, Deeb L, et al. Insulin treatment in children and adolescents with diabetes. Pediatr Diabetes 2014; 15 Suppl 20: 115-134.

8 Phelan H, Clapin H, Bruns L, et al. The Australasian Diabetes Data Network: first national audit of children and adolescents with type 1 diabetes. Med J Aust 2017; 206: 121-125.

9 Miller KM, Foster NC, Beck RW, et al. Current state of type 1 diabetes treatment in the US: updated data from the TID Exchange Clinic Registry. Diabetes Care 2015; 38: 971-978.

10 Witsch M, Kosteria I, Kordonouri O, et al. possibilities and challenges of a large international benchmarking in paediatric diabetology; the SWEET experience. Pediatr Diabetes 2016; 17 Suppl 23: 7-15. 